\title{
UAt $00-3801$
}

\section{LA-UR-9X-XXXXX-}

Approved for public release;

distribution is unlimited

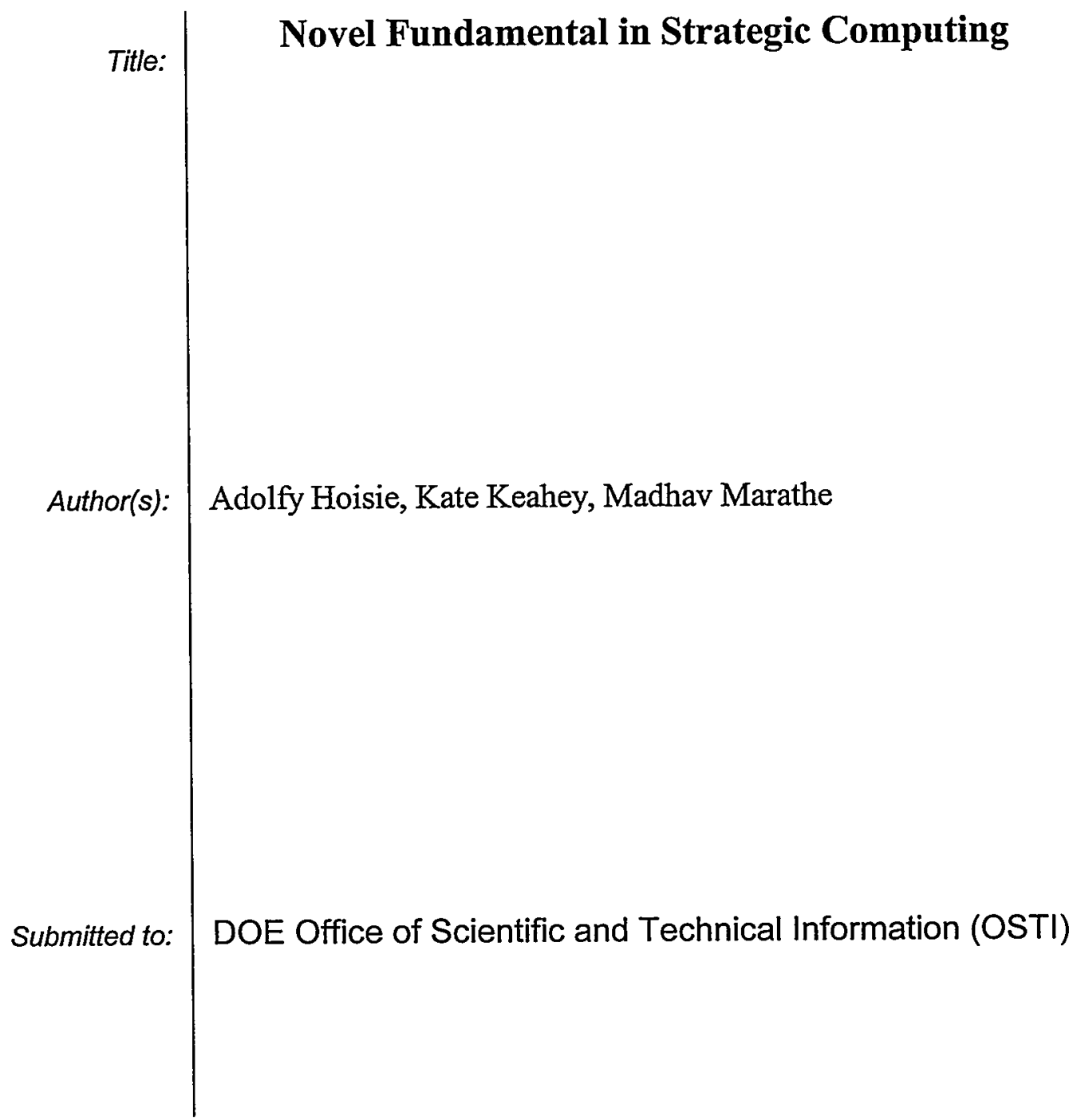

\section{Los Alamos \\ MATIOH GL LAEORATORY}




\section{DISCLAIMER}

This report was prepared as an account of work sponsored by an agency of the United States Government. Neither the United States Government nor any agency thereof, nor any of their employees, make any warranty, express or implied, or assumes any legal liability or responsibility for the accuracy, completeness, or usefuiness of any information, apparatus, product, or process disclosed, or represents that its use would not infringe privately owned rights. Reference herein to any specific commercial product, process, or service by trade name, trademark, manufacturer, or otherwise does not necessarily constitute or imply its endorsement, recommendation, or favoring by the United States Government or any agency thereof. The views and opinions of authors expressed herein do not necessarily state or reflect those of the United States Government or any agency thereof. 


\section{DISCLAIMER}

Portions of this document may be illegible in electronic image products. Images are produced from the best available original document. 


\title{
Novel Fundamentals in Strategic Computing
}

\author{
Adolfy Hoisie *, Kate Keahey, Madhav Marathe
}

BECRPED

DEC 132000

Abstract

OSTI

This is the final report of an initially funded for three-year, LaboratoryDirected Research and Development (LDRD) project at the Los Alamos National Laboratory (LANL). The funding was zeroed after the first year at the time of the $6 \%$ to $4 \%$ reduction in LDRD funding. All the information in this report describes the work done in this single year of research.

We carried out research in common component architectures, performance modeling and models of computations related to deep memory hierarchies. The goal of this first year was to create to basis for the integrated approach to the analysis and modeling of the software-hardware-algorithms realities of computing driven by non-scientific applications.

\section{Importance to LANL's Science and Technology Base and National R\&D Needs}

Computational science is of paramount strategic importance at the Laboratory. The computational needs of programs such as ASCI require computer systems and software of unprecedented scale and complexity. However, the computing landscape of tomorrow is likely to be very different. The development of microprocessors, networks, software and algorithms is no longer driven to the needs of scientific computing. In fact, applications such as multimedia, web-applications and data mining are the new driver apps for computing systems and networks. Given a COTS approach to building extremescale hardware and software systems, the question arises as to whether the COTS of tomorrow will allow us to achieve the computing goals at the Laboratory. This project intended to address many of the inter-related areas in answering this question

\section{Scientific Approach and Accomplishments}

Software, hardware, and algorithms are continually increasing in size and/or complexity, resulting in large, compositional systems. They are engineered by systematically combining smaller, well-understood components. Despite this trend, the techniques for building such systems are poorly understood. Our project adds insight into compositional software, hardware, and algorithms.

This year we developed a high-level design and implemented a prototype of a component architecture for high-performance scientific applications. This concrete implementation 
will allow us to experiment and empirically evaluate techniques and abstractions, as well as provide a vehicle for building actual multicomponent applications. In collaboration with scientists from academia and other national laboratories, we made significant progress in formulating an interoperability standard for high-performance computing component architectures: the Common Component Architecture.

We carried out extensive research on existing memory models of computation. From a theoretica1/practical standpoint we have identified the models of Alpern et al. and Vitter et al. as suitable for future exploration. We also studied different memory-efficient algorithms for linear-relaxation-type problems that have been proposed in the literature. As a step toward building a robust complexity theory for memory-centric computation, we have begun identifying generic algebraic specifications that can be used to represent large classes of seemingly unrelated problems in the same framework. We have also begun to identify necessary characteristics of transformations (reductions) that can be used to establish equivalence classes of problems under a given computational model.

We initiated a performance evaluation of commodity processor architectures with the intention of studying their performance on ASCI and "driver" (multimedia, web, and data-mining) applications. We then created a preliminary set of multimedia benchmark codes, which cover a variety of mass-market applications. We have developed a novel hardware-counter-based instruction-level analysis technique that is suited for characterizing multimedia and other commercial applications. We also proposed a methodology for performance modeling and prediction of large-scale scientific applications, which we then used to characterize one major ASCI application.

\section{Publications}

Armstrong, R., et al., "Toward a Common Component Architecture for High Performance Scientific Computing," in Proc. 8th IEEE International Symposium on High Performance Distributed Computing (August 1999).

Barrett, C., et al., "Formal Language Constrained Path Problems" (to be published in SIAM J. Computing).

Cameron, K.W., and Y. Luo, "Instruction-Level Microprocessor Modeling of Scientific Applications," in Lecture Notes in Computer Science 1615 (Springer-Verlag, Berlin, 1999), p. 29.

Carr, R., et al., "On the Red-Blue Set Cover Problem" (submitted to 11th ACM-SIAM Symposium on Discrete Algorithms [SODA], July 1999).

Doddi S., et al., "Point Set Labeling with Specified Positions" (submitted to 11th ACMSIAM Symposium on Discrete Algorithms [SODA], July 1999).

Hoisie, A., et al., "Performance Analysis of Large-Scale Applications Based on Wavefront Algorithms," in Proceedings of the NASA HPCCP/CAS Workshop (January 1999), p. 15. 
Hoisie, A., et al., "Performance Analysis of Wavefront Algorithms on Very-Large Scale Distributed Systems," in Lecture Notes in Control and Information Sciences 249 (Springer-Verlag, Berlin, 1999), p. 171.

Hoisie, A., et al., "Scalability Analysis of Multidimensional Wavefront Algorithms on Large-Scale SMP Clusters," in Proceedings of the 7th Symposium on the Frontiers of Massively Parallel Computations (February 1999), p. 5.

Hunt, H.B. III, et al., "On the Efficient Approximability of 'HARD' Problems: A Survey," in Proceedings of Approximation and Complexity in Numerical Optimization: Continuous and Discrete Problems, P.M. Pardalos, Ed. (Kluwer Academic Publishers, Norwell, MA, 1999).

Hunt, H.B. III, et al., "Parallel Approximation Schemes for a Class of Planar and Near Planar Combinatorial Problems" (to be published in Information and Computation).

Joubert, W., et al., "Domination Problem with Edge Covering Constraints" (11th ACMSIAM Symposium on Discrete Algorithms [SODA], July 1999).

Krumke, S.O., et al., "Improving Spanning Trees by Upgrading Nodes" (to be published in Theoretical Computer Science).

- Krumke, S.O., et al., "Upgrading Bottleneck Constrained Forests" (to be published in Discrete Applied Mathematics).

Luo, Y., and K.W. Cameron, "Instruction-Level Characterization of Scientific Computing Applications Using Hardware Performance Counters," in Workload Characterization: Methodology and Case Studies (IEEE-CS Press, 1999), p. 90.

Sun, X.H., et al., "A Factorial Performance Evaluation for Hierarchical Memory Systems," in Proceedings of IPPS'99 (San Juan, Puerto Rico, April 1999), p. 70. 